25. Gupta, U. C., A simplified method for determining hot-water soluble boron in podzol soils. Soil Sci., 1967, 103, 424-428.

26. Gaines, T. P. and Mitchell, G. A., Boron determination in plant tissue by the azomethine-H method. Commun. Soil Sci. Plant Anal., 1979, 10, 1099-1108.

27. Walworth, J. L. and Sumner, M. E., The diagnosis and recommendation integrated system (DRIS). Adv. Soil Sci., 1987, 6, 149-188.

28. Bhargava, B. S., Leaf analysis for nutrient diagnosis, recommendation and management in fruit crops. J. Indian Soc. Soil Sci., 2002, 50, 352-373.

29. Behera, S. K. et al., Spatial variability of some soil properties varies in oil palm (Elaeis guineensis Jacq.) plantations of west coastal area of India. Solid Earth, 2016, 7, 979-993.

30. Lee, C. T., Rahman, Z. A., Musa, M. H., Norizan, M. S. and Tan, C. C., Leaf nutrient concentrations in oil palm as affected by genotypes, irrigation and terrain. J. Oil Palm Environ., 2011, 2, $38-47$.

31. Behera, S. K., Suresh, K., Ramachandrudu, K., Manorama, K. and Rao, B. N., Mapping spatial variability of leaf nutrient status of oil palm (Elaeis guineensis Jacq.) plantations in India. Crop Pasture Sci., 2016, 67(1), 109-116; doi: 10.1071/CP15029.

Received 9 November 2018; accepted 20 May 2019

\section{Crustal depth estimation over the Indian lithospheric plate using satellite geoid and a gravimetric-isostatic model}

\section{T. J. Majumdar* \\ Space Applications Centre (ISRO), Ahmedabad 380 015, India}

\begin{abstract}
Moho depth or simply, Moho, in general, describes the boundary between the earth's crust and the mantle and is a very important geophysical parameter. It is also related to the earth's crustal thickness at any point. Geoid and gravity anomalies derived from satellite altimetry are gradually gaining importance in marine geo-scientific investigations. However, satellite gravity technique is not working over land/continent. So, we need to develop technique like the VMM model which is equally working over land. In addition of generating crustal thickness, it also saves energy to generate Bouguer anomaly over land and ocean.
\end{abstract}

Keywords: Crustal depth, geoid, gravity anomaly, lithospheric plate, satellite altimetry

THE Mohorovičić discontinuity or Moho is one of the most important geophysical parameters for defining the

*e-mail: tapan.j.majumdar@gmail.com subsurface crustal thickness. It also defines the boundary between the earth's crust and mantle. Gravity field models (mostly via satellites) are being used for a variety of geophysical and oceanographic explorations. Surface gravity data also generate the gravity field, but acquiring data uniformly over the earth is difficult and timeconsuming. Since the sea surface largely conforms to the geoid, satellite altimetry provides precise measurements of the marine gravity field, provided that proper corrections are made to altimeter data and other relevant errors ${ }^{1}$.

Now-a-days, it is possible to generate large-scale altimeter-derived residual/prospecting geoid and gravity anomaly maps over the oceans. They are used to infer subsurface geological structures analogous to gravity anomaly maps generated through ship-borne surveys. Geoid is generated by the equipotential surface over the oceans $^{2-4}$, which contains information regarding mass distribution inside the entire earth. Geoid is then converted to gravity using a simple technique ${ }^{4,5}$. Gravity anomaly maps provide information on the subsurface density distribution, major tectonic and structural lineaments, geodynamic aspects of a plate margin and structure of the crust and lithosphere ${ }^{6}$. However, satellite gravity technique cannot be used over land/continent. So, we need to develop a technique like the Vening MeineszMoritz (VMM) model which works equally well over land for generating crustal thickness ${ }^{7}$. It also helps generate Bouguer anomaly over land and ocean.

An improved spherical harmonic model of the earth's gravitational potential up to degree and order 360 has been generated by NASA, NIMA and OSU (USA) ${ }^{8}$. The Earth Gravitational Model 1996 (EGM96) incorporates improved surface gravity data. A very high-resolution geoid (spatial resolution as high as $\sim 4 \mathrm{~km}$ ) and gravity anomalies have been generated from ERS-1, Seasat, GeosatGeodetic Mission (GGM) and TOPEX/POSEIDON data $^{4,8}$. The Bouguer gravity map brings out the following striking features ${ }^{9-11}$ : (i) Dominance of negative Bouguer anomalies over a major part of the Indian subcontinent, reaching a maximum value of $380 \mathrm{mGal}$ over the Himalayas. (ii) Belts of positive Bouguer anomalies are seen along the west coast. Positive anomaly trends characterize part of the east coast and the Shillong plateau. (iii) The trends of anomalies are parallel to the major structural trend: NNW-SSE Dharwar trend in South India, NE-SW Aravalli trend and the Himalayan trend ${ }^{9-11}$. (iv) Several gravity highs and lows can also be identified. Figure 1 shows the residual geoid anomaly map generated using high-resolution altimeter data over oceans surrounding Indian peninsula. The bathymetric and tectonic features as observed in the residual geoid image are given elsewhere ${ }^{3,4}$. They provide important information on the structure of the compensated lithosphere.

The Bouguer anomaly map of India has also been digitized and the values interpolated at $10 \mathrm{~km}$ interval to 


\section{RESEARCH COMMUNICATIONS}
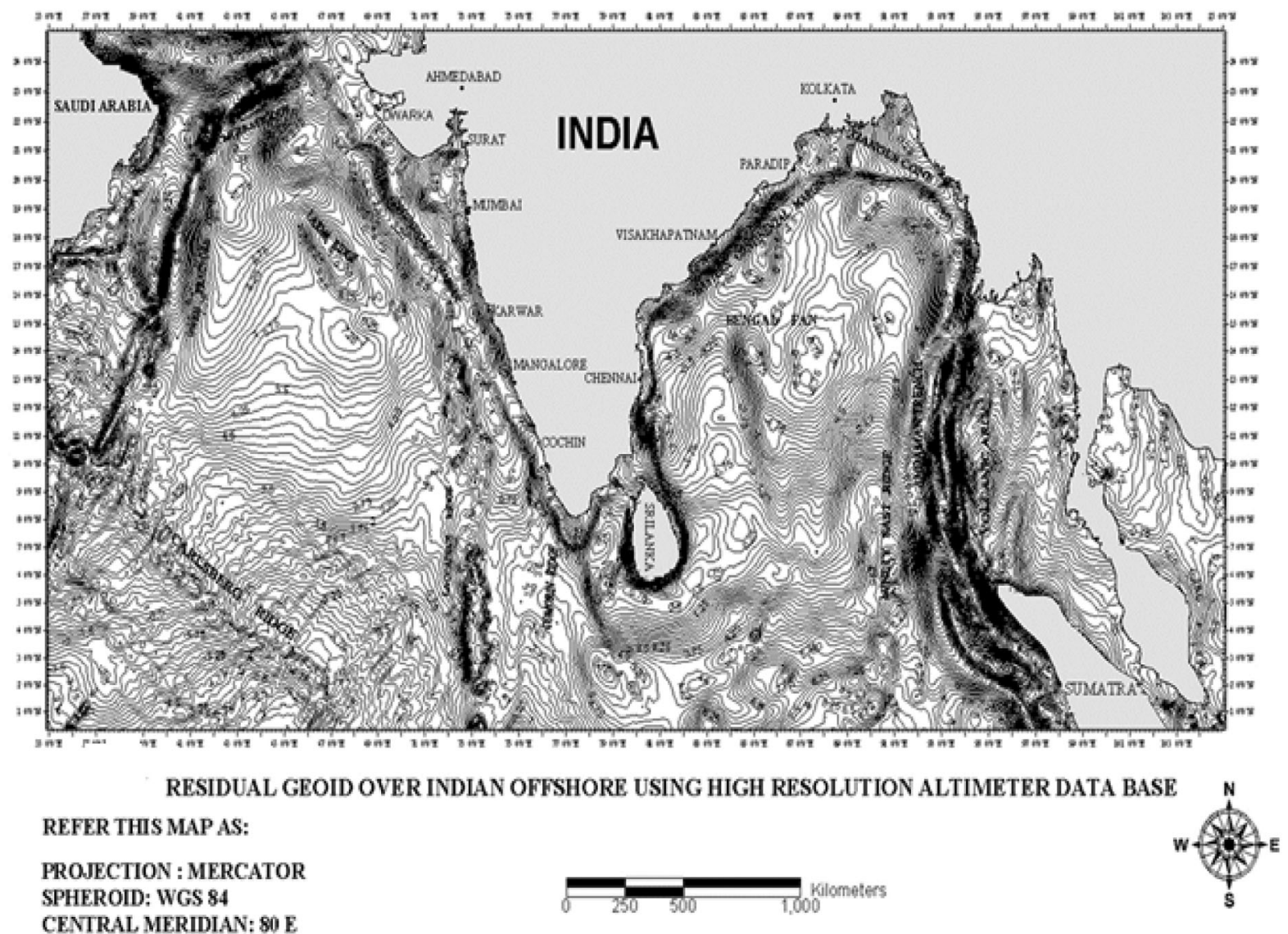

CENTRAL MERIDIAN: $80 \mathrm{E}$

SCALE 1: 15,000,000

CONTOUR INTERVAL : $0.25 \mathrm{~m}$.

Figure 1. Residual geoid over Indian offshore using high-resolution satellite data (after Majumdar and Bhattacharyya ${ }^{4}$ ).

prepare a composite gravity map of the country ${ }^{10}$. The gravity data for oceans are based on the EGM96 data ${ }^{8}$. The satellite data provide free-air anomaly at $30^{\prime} \times 30^{\prime}$ grid for the Arabian Sea and the Bengal basin, which are joined with the Bouguer anomaly of Indian continent. The two are matched properly along the coast and Figure 2 presents the resulting gravity map, which depicts several gravity anomalies corresponding to important tectonic elements over the oceans and the continents. The gravity highs of $90^{\circ} \mathrm{E}$ Ridge spread along the continental shelf of West Bengal, India and Bangladesh, and join with the gravity high of $85^{\circ} \mathrm{E}$ Ridge $\mathrm{R}^{3,4}$. Pal et al. ${ }^{12}$ have generated a revised gravity anomaly map from the EIGEN6C4 highresolution global gravity model, and utilized it for understanding the structure and tectonics over the $85^{\circ} \mathrm{E}$ Ridge and its surroundings.

The Moho is the interface between the crust and the mantle, although with variable thickness of the transition zone, depending on the tectono-magmatic setting ${ }^{13}$. Mechie et al. ${ }^{14}$ reviewed the crustal structure of the Arabian Plate and its margins based on the available seismological data. They presented a map of depth to Moho based purely on seismological data. Moho depth is typi- cally $32-45 \mathrm{~km}$ in the interior of the Arabian Plate and more than $50 \mathrm{~km}$ below the Zagros mountains ${ }^{13,14}$.

Modelling of the boundary between the earth's crust and the upper mantle has been done by Bagherbandi ${ }^{15}$ using a gravimetric-isostatic model in a global scale. The VMM problem is used to determine the Moho depth such that the compensating attraction totally balances the Bouguer gravity anomaly on the earth's surface, implying that the isostatic anomaly vanishes on the earth's surface. Here, a practical method to recover the Moho depth from the gravity data is used based on the VMM technique ${ }^{15-17}$.

In general, recovery of the crustal thickness from gravity anomaly is a difficult problem. This needs convergence of the solution using an iterative method. However, the method presented by Sjoberg ${ }^{17}$ is independent from the regularization method and any iteration. This is the main advantage of the VMM model.

In this study, the VMM model is used to estimate the Moho depth over the Indian Plate. The results are determined using the latest Earth Gravitational Model EGM2008 (EGM08) and Digital Topographic Model (DTM2006) up to degree and order 90 corresponding to $2^{\circ} \times 2^{\circ}$ grid over the Indian subcontinent and its 


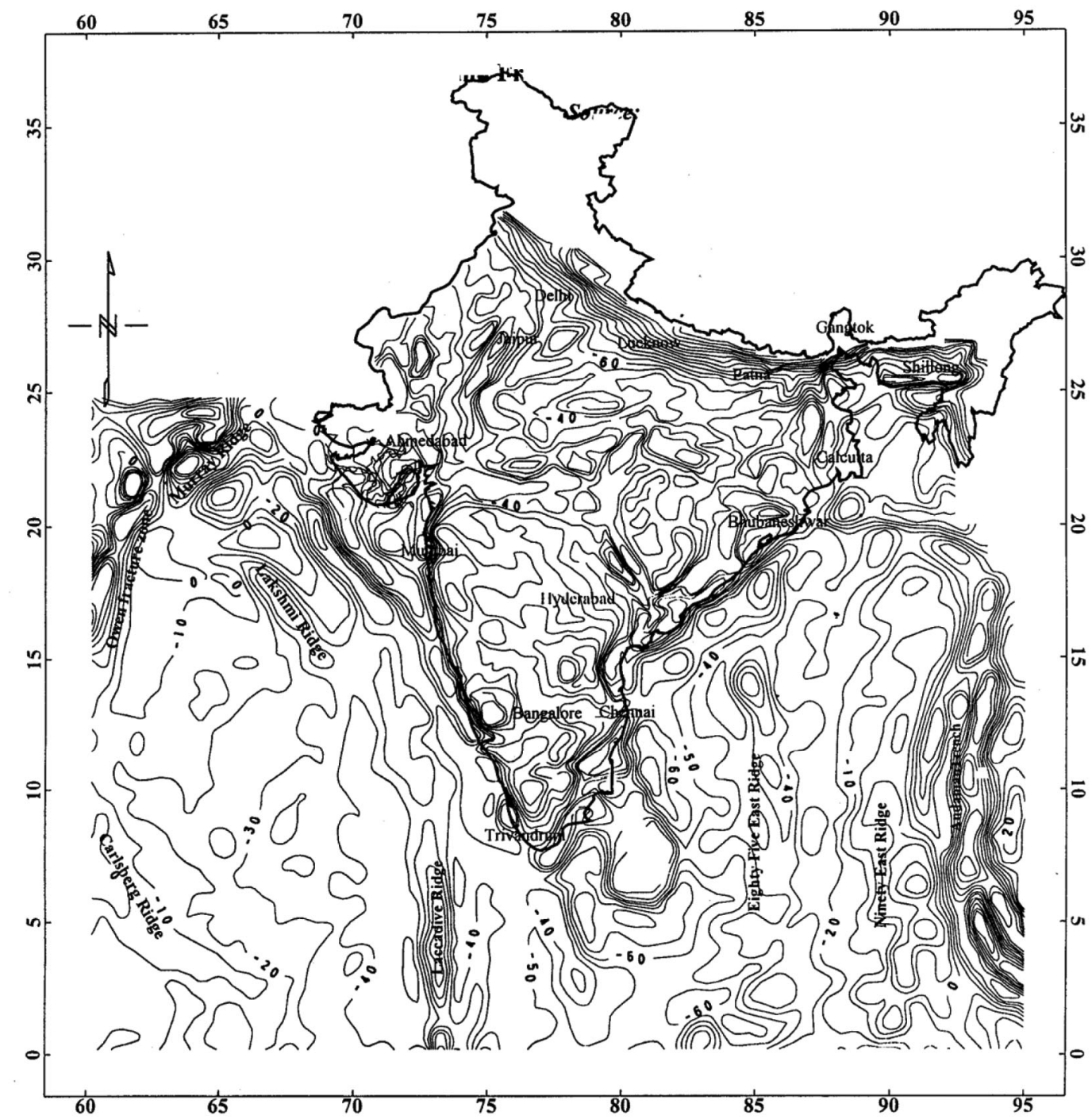

Figure 2. Bouguer anomaly over continent and free-air anomaly over the adjoining oceans of India. (Source: NGRI, 1978 and GSB, 1990 for continent, and EGM96 for ocean region) ${ }^{3}$.

surroundings ${ }^{18}$. The study area is selected between $0^{\circ}$ $30^{\circ} \mathrm{N}$ and $55^{\circ}-105^{\circ} \mathrm{E}$. As shown by Bagherbandi ${ }^{15}$, the MATLAB program uses these data to determine the global approximate Moho depth (T1), which varies between 32 and $61 \mathrm{~km}$ (approx.).

$$
\Delta g I(P)=\Delta g B(P)+A c(P)=0,
$$

where $A c(P)$ is the compensating attraction, $\Delta g B(P)$ the Bouguer gravity anomaly over the earth's surface and $\Delta g I(P)$ is the isostatic anomaly which totally vanishes on the earth's surface.

Equation (1) is the fundamental equation for determining the crustal thickness isostatically ${ }^{15}$.

Determination of the depth of the Moho boundary over a part of the Indian Plate could be achieved. However, this needs realistic density data for crust and topography.
The MATLAB code used by Bagherbandi ${ }^{15}$ needs global EGM and solid earth topography data for determining the crustal thickness by a gravimetric-isostatic model, i.e. the VMM model. The real earth is complicated compared to our assumption for the VMM model. Another problem that Bagherbandi ${ }^{15}$ faced was lack of terrestrial gravity data to compute crustal thickness, which is the main reason for using EGM08 instead of terrestrial data. Generation of Bouguer anomaly data over land by geophysical instruments is also a challenging task. Luckily, data collection over the Indian landmass by $\mathrm{NGRI}^{10}$ is comparatively satisfactory. In this context, the present approach is useful and attemptable and is standing on a robust model $(\mathrm{VMM})$ as described by Sjoberg ${ }^{17}$, Bagherbandi ${ }^{15}$, etc.

In the present case, Bouguer gravity over the Indian Plate could be estimated using terrestrial and satellite geoid/gravity data (Figure 2). The Bouguer gravity 


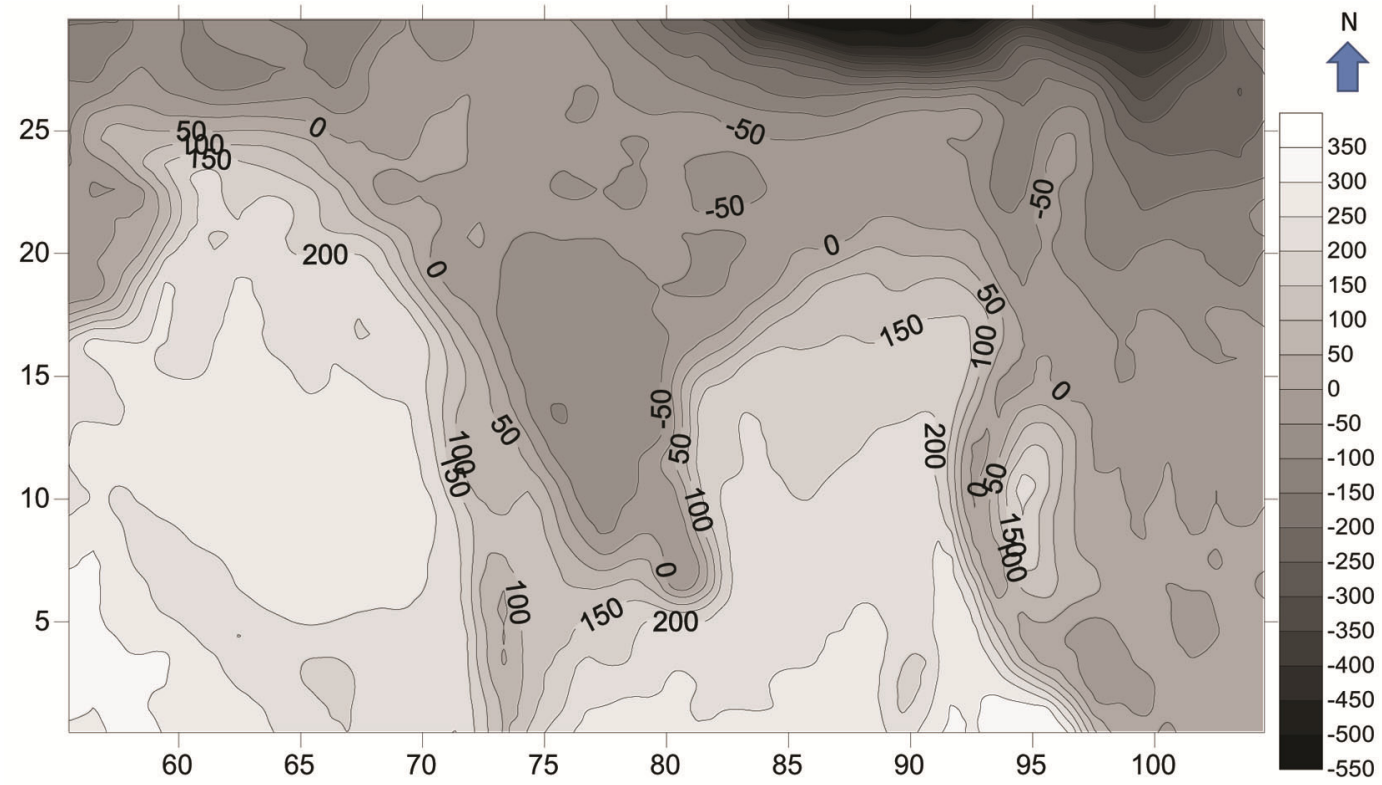

Figure 3. Bouguer gravity anomaly over the Indian plate using the VMM model (contour interval $\sim 50 \mathrm{mGal}$ ).

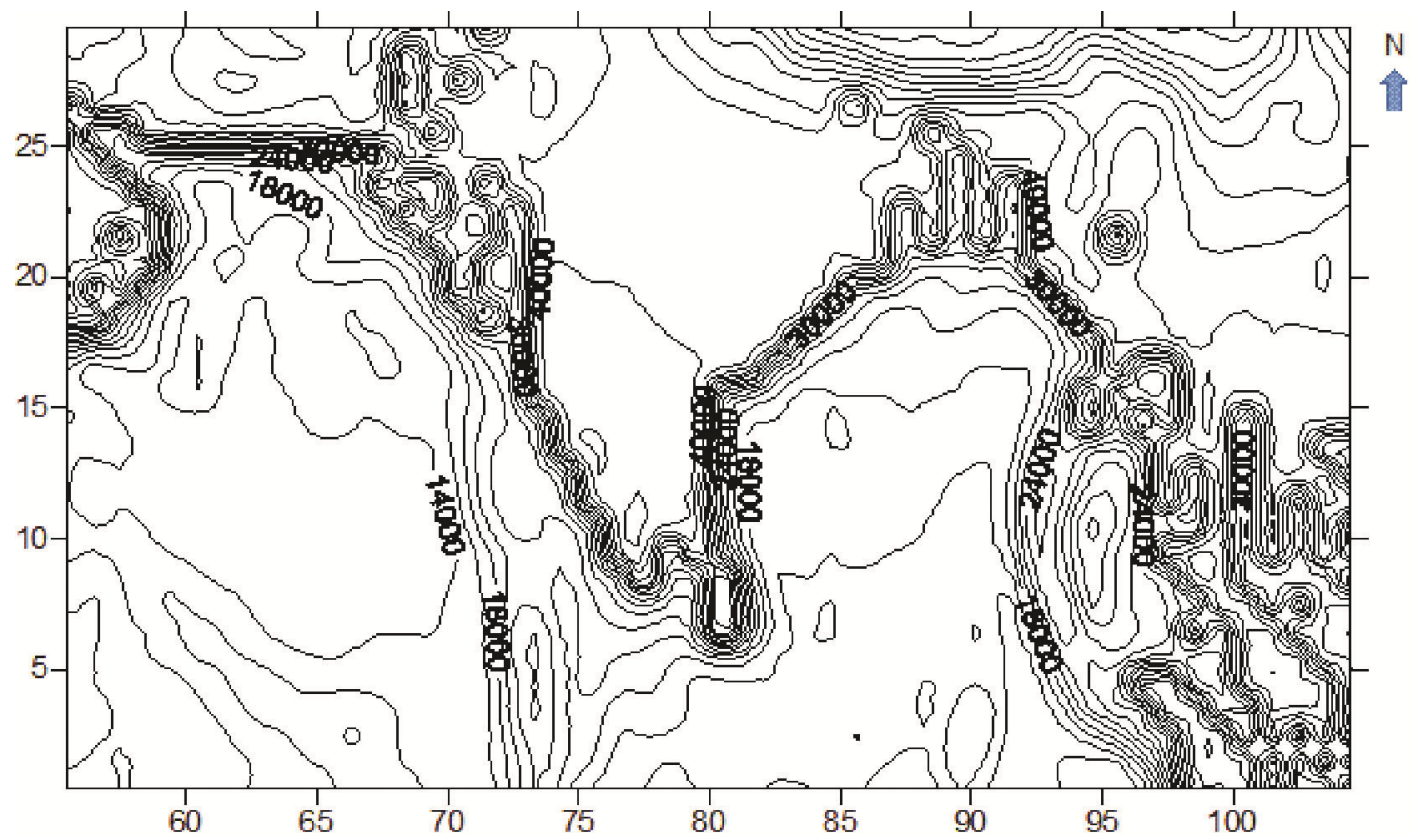

Figure 4. Crustal thickness (Moho depths) across the Indian plate using the VMM model (contour interval 2000 $\mathrm{m}$ ).

anomaly ranges over the Indian Plate as estimated using the VMM model and terrestrial data match satisfactorily (Figures 2 and 3; between -50 and $200 \mathrm{mGal}$ in both cases). The other verification is estimated Moho across the $15^{\circ} \mathrm{N}$ (long $80^{\circ}-92^{\circ} \mathrm{E}$ ) profile. Subsurface structures with crustal depths (Figure 4) could be identified with Moho variation within the range $10-20 \mathrm{~km}$ (ref. 19). The Moho/crustal depths as generated by the VMM model ${ }^{15}$ across the profile vary within expected ranges (Figure 4) satisfactorily, when compared with the lithospheric anomaly variation using integrated analysis of bathymetry, gravity, geoid and multichannel seismic data ${ }^{19}$. Moho depths are, in general, well below the lithosphere. Validation of the VMM model over parts of the Indian Plate could thus be achieved using terrestrial geoid/gravity data. Generation of Bouguer anomaly (Figure 3) using the VMM model over the Indian land mass is useful and time-saving, as the in situ gravity data generation is 
highly strenuous and time-consuming. The Bouguer anomaly using in situ observations can also be validated using such model results. Alternatively, gravimetric geoid can be generated over the Indian subcontinent using the VMM model. Validation of in situ/altimetry-derived Bouguer anomaly over the Indian land mass and its surroundings, and comparison with VMM-derived Bouguer gravity is a novel approach. Here the Moho depth could be estimated from the gravity data using the VMM model.

1. Nerem, R. S., Jekeli, C., Koblinisky, J. and Beckley, B. D., A preliminary evaluation of ocean topography from the TOPEX/POSEIDON mission. J. Geophys. Res., 1994, 99, 2456524583.

2. Sandwell, D. T. and Smith, S., Marine gravity anomaly from Geosat and ERS 1 satellite altimetry. J. Geophys. Res., 1997, 102(B5), 10039-10054

3. Majumdar, T. J., Mohanty, K. K., Mishra, D. C. and Arora, K., Gravity image generation over the Indian subcontinent using NGRI/EGM96 and ERS-1 altimeter data. Curr. Sci., 2001, 80(4), 542-554.

4. Majumdar, T. J. and Bhattacharyya, R., An atlas of very high resolution satellite geoid/gravity over the Indian offshore. SAC Technical Note No. SAC/RESIPA/MWRG/ESHD/TR-21/2004, p. 48.

5. Haxby, F., Karner, G. D., La Brecque, J. L. and Weissel, J. K., Digital images of combined oceanic and continental data sets and their use in tectonic studies. EOS Trans. Am. Geophys. Union, 1983, 64, 995-1004.

6. Ram Babu, H. V., Gravity image of India. Curr. Sci., 1999, 76, 1533-1535.

7. Eshagh, M., Bagherbandi, M. and Sjoberg, L. E., A combined global Moho model based on seismic and gravimetric data. Acta Geod. Geophys. Hung., 2011, 46(1), 25-38; doi:10.1556/ AGeod.46.2011.1.3.

8. Lemoine, F. G., et al., The development of the joint NASA GSFC and the National Imagery and Mapping Agency (NIMA) Geopotential model EGM96. NASA/GSFC Publ. No. NASA/TP-1998206861, 1998

9. Mahadevan, T. M., Deep continental structure of India: a review. Mem. Geol. Soc. India, 1994, 28, 569

10. NGRI Map Series, Gravity Map Series of India (1:5 million). National Geophysical Research Institute, Hyderabad, 1978, 1 st edn.

11. Verma, R. K. and Subrahmanyam, C., Gravity anomalies and the Indian lithosphere: review and analysis of existing gravity data. Tectonophysics, 1984, 105(1-4), 141-161.

12. Pal, S. K., Narayan, S., Majumdar, T. J. and Kumar, U., Structural mapping over the $85^{\circ} \mathrm{E}$ ridge and surroundings using EIGEN6C4 high-resolution global combined gravity field model: an integrated approach. Mar. Geophys. Res., 2016, doi:10.1007/s11001-0169274-3.

13. Thybo, H. et al., Moho: 100 years after Andrija Mohorovičić. Tectonophysics, 2013, 609, 1-8.

14. Mechie, J. et al., The distribution of Moho depths beneath the Arabian plate and margins. Tectonophysics, 2013, 609, 234-249.

15. Bagherbandi, M., MohoIso: a MATLAB program to determine crustal thickness by an isostatic and a global gravitational model. Comput. Geosci., 2012, 44, 177-183.

16. Heiskanen, W. A. and Moritz, H., Physical Geodesy, W H Freeman and Co, San Francisco, USA, 1967, p. 364

17. Sjoberg, L. E., Solving Vening Meinesz-Moritz inverse problem in isostasy. Geophys. J. Int., 2009, 179(3), 1527-1536; doi:10.1111/j.1365-246X.2009.04397.x.
18. Pavlis, N. et al., An earth gravitational model to degree 2160: EGM08. Presented at the 2008 General Assembly of the European Geosciences Union, Vienna, Austria, 13-18 April 2008.

19. Rao, G. C. et al., Lithosphere structure and upper mantle characteristics below the Bay of Bengal. Geophys. J. Int., 2016, 206, 675-695.

ACKNOWLEDGEMENTS. I thank Prof. M. Bagherbandi (University of Gävle, Sweden) for help in generating the VMM modelled data over the Indian Plate. I also thank the editor/reviewers for their critical comments.

Received 22 October 2018; revised accepted 8 May 2019

doi: $10.18520 / \mathrm{cs} / \mathrm{v} 117 / \mathrm{i} 3 / 502-506$

\section{Geostationary satellite-based observations for ocean applications}

\section{Neeraj Agarwal*, Rashmi Sharma, Pradeep Thapliyal, Rishi Gangwar, Prateek Kumar and Raj Kumar}

Earth, Ocean, Atmosphere and Planetary Sciences Area, Space Applications Centre, Indian Space Research Organisation, Ahmedabad 380 015, India

The study presents assessment and potential oceanographic applications of sea-surface temperature (SST), ocean net shortwave radiation (SWR) and chlorophyll concentration (CC) observations obtained from various geostationary platforms. SST and SWR from imager on-board Indian National Satellite (INSAT3D) and CC from Global Ocean Color Imager (GOCI) on-board communication ocean and meteorological satellite (COMS) have been used in the analysis. Relative advantages of high temporal resolution obtained from the geostationary platform compared to polar orbiting platforms are demonstrated. Comparison of INSAT-3D SST with observations gives a correlation of 0.85 and RMSE of $0.81 \mathrm{~K}$. These platforms definitely provide a highly reliable source of continuous observations, which is useful in monitoring dynamic oceanic features such as thermal fronts, chlorophyll blooms, air-sea exchange fluxes, etc. on diurnal to daily timescales.

Keywords: Chlorophyll concentration, geostationary satellites, INSAT-3D, sea-surface temperature, shortwave radiation.

OVER the next few years, a constellation of advanced meteorological geostationary (GEO) satellites (CGMS-46,

*For correspondence. (e-mail: neeraj@sac.isro.gov.in) 